\title{
Filosofia africana para afrorreferenciar o currículo e o pertencimento
}

\author{
Adilbênia Freire Machado' \\ Sandra Haydée Petit2
}

\begin{abstract}
RESUMO
Este artigo pretende trazer alguns pontos de partidas para um currículo afrorreferenciado e que possa potencializar o pertencimento de cada um, cada uma de nós. Para isso, trabalhamos com a filosofia africana e a filosofia do encantamento, apresentando experiências de práticas curriculares afrorreferenciadas, especialmente desde a pretagogia e os marcadores das africanidades. Concluímos que os conteúdos e a(s) forma(s) de transmissão precisam andar juntos, não mais de forma hierarquizada e bancária, mas preferencialmente iniciática, no seu sentido amplo.
\end{abstract}

Palavras-chave: Filosofia Africana. Currículo Afrorreferenciado e Pertencimento. Pretagogia.

\section{African philosophy to afro-refer the curriculum and belonging}

\begin{abstract}
This article aims to address some starting points for an afro-referenced curriculum that may potencialize belonging in each one of us. Therefore, we work on African philosophy and Philosophy of Enchantment, presenting experiences based on afroreferenced curricula practices, especially Pretagogy and the marks of africanities. We conclude that the contents and form of transmission must work together, not with hierarquies and a unilateral form of teaching, but preferentially in an iniciatic way, in a large sense.
\end{abstract}

Keywords: African Philosophy. Afro-referenced Curriculum and Belonging. Pretagogy.

'Doutora em Educação (UFC/Universidade Federal do Ceará). NACE (Núcleo das Africanidades Cearenses/UFC); Rede Africanidades (UFBA); ABPN (Associação Brasileira de Pesquisador@s Negr@s); AAFROCEL (Academia Afrocearense de Letras). ORCID ID: https://orcid.org/0000-0003-3226-2139 E-mail: adilmachado@yahoo.com.br

2 Doutora em Ciência da Educação (Paris VIII). Faculdade de Educação /UFC; NACE (Núcleo das Africanidades Cearenses /UFC) - Ceará. ORCID ID: https://orcid.org/0000-00022601-3534 E-mail: novanegapetit@gmail.com 


\section{Filosofía africana para afrorreferenciar el currículo y la pertenencia}

\section{RESUMEN}

Este artículo tiene como objetivo comprender algunos puntos de partida para lograr un currículo afroreferenciado y que pueda potenciar el sentido de pertenencia en cada uno de nosotros. Para ello, trabajamos con la filosofía africana y la filosofía del encantamiento, presentando experiencias que tienen como base prácticas curriculares afroreferenciadas, sobre todo la pedagogía y los marcadores de africanidades. Se concluye que los contenidos y la forma de transmitirlos deben estar unidos y no de forma jerarquizada, así como de preferencia de un modo iniciático, en el sentido amplio.

Palabras clave: Filosofía Africana. Currículum Afrorreferencia. Pedagogía.

\section{Abrindo}

Trazemos aqui nossas reflexões acerca do que pode constituir um currículo empretecido, afrorreferenciado, partindo da problemática que atravessa a educação brasileira, a saber, a colonialidade que ainda marca o currículo de um país fundado no trauma originário da invasão, com seu rastro de genocídios, desterros e escravização. Enfrentando as tentativas totalitárias de aniquilamento físico e apagamento histórico filosófico, os povos originários e os povos negros têm lutado ao longo de mais de 500 anos por uma educação que preserve e atualize as suas ancestralidades, para além da excessiva hegemonia das culturas eurocentradas como modelo único de civilização. Focando o aporte filosófico e pedagógico da negritude desterrada, mas que hoje coloca-se de modo cada vez mais afirmativo, mostramos exemplos de ampliação do conceito estreito de educação e pedagogia construído nos currículos escolares e universitários brasileiros. Partindo do nosso estudo bibliográfico e das nossas numerosas pesquisas, intervenções e experiências de formação que geraram novos conceitos, como a Pretagogia e a Filosofia do Encantamento, apresentamos, além da problemática de apagamento do Negro na educação, as lutas pela superação dessa invisibilização, discutindo o que, a nosso ver, fundamenta hoje um currículo afrorreferenciado, de modo filosófico e teórico operacional, desde as cosmopercepções africanas. 


\section{Tessituras sobre o que está posto}

Pensar (em uma perspectiva da ação) sobre o que quer um currículo negro é ponderar, mexer, no campo político do poder, nos diversos processos de colonização que perpassam o tempo e nos acompanham dia a dia. Temos um currículo monocultural, eurocentrado, racista, machista e silenciador de diversas culturas que nos formaram e o processo de mudança é lento, árduo, entretanto, absolutamente necessário em tempos em que a descolonização é uma ação própria de re-existência, de encantamento pela vida. Em nosso caso, há silenciamento, invibilização, inferiorização e negativização da importância fundante da participação de várias culturas africanas na construção do nosso país, na tessitura de quem somos nós, brasileiras e brasileiros.

Sabemos que o currículo é um espaço de significação "estreitamente vinculado ao processo de formação de identidades sociais" (SILVA, 2010, P. 27) e a "identidade, tal como a cultura, tampouco é um produto final, acabado" (Ibid, p. 25). Desse modo, compreendemos que "o fortalecimento da identidade nacional não pode ser pleno enquanto mantivermos um silenciamento de qualquer elemento constitutivo desta identidade" (FLOR DO NASCIMENTO, 2012, p. 81). Nesse sentido, somos "conclamados a retornar ao continente africano, sem estereotipá-lo, para entender aquilo que nos constitui historicamente" (Idem). Esse retorno é mediado continuamente por nossa ancestralidade africana que perpassa o tempo e nos fortalece cotidianamente.

Assim, compreendemos que a saída desse silenciamento permite conhecermos uma diversidade que nos agrega valores, nos tornando pessoas encantadas, que buscam continuamente o bem estar de si, e de todos/as, pois na cosmopercepção africana somos como uma teia de aranha e quando se mexe em um canto da teia todo o resto é implicado, pois somos todos/as parte de uma mesma teia... parte do inteiro e o inteiro de uma parte! SOMOS COM!

O encantamento é, pois, uma política de sentidos, implicação que leva a produções epistêmicas, ações inclusivas, currículos reflexivos, 
descolonizados e plurais, potencializando nosso pertencimento. O desencantamento permeia continuamente, pois somos seres de sentidos e sentimentos, seres em movimento e esse desencantamento nos leva a reflexões críticas sobre nossas ações e outras percepções dos espaços onde vivemos. Assim, o encantamento caracteriza-se por ser a estética do viver bem... das experiências que tecem o bem-viver, ser em movimento, em comunidade, no coletivo, em uma relação íntima com nossa ancestralidade, nosso pertencimento, nossa espiritualidade (SOMÉ, 2003). Pois, nos interessa profundamente "conhecer e nos inspirar daquilo que potencializa nossa busca de bem viver, em consonância com a conexão ancestral" (PETIT, 2018, p. 117).

\section{Lei 10.639 / 2003: luta e implicação curricular}

Décadas de várias mobilizações sociais, ações políticas, negociações e estratégias de diversos movimentos negros e intelectuais submergidos/as na busca de uma política antirracista, inclusiva, portanto, transformadora da realidade, especialmente do povo negro, levaram ao surgimento da Lei 10.639/2003, que altera a Lei 9394/1996 de 20 de dezembro, que estabelece as Diretrizes e Bases da Educação Nacional (LDB).

A Lei 10.6393, promulgada em nove de janeiro de 2003, deu origem ao Parecer CNE/CP n. 003/2004, em que Petronilha Beatriz Gonçalves e Silva foi relatora. O referido Parecer regulamenta a Lei 10.639/2003 e indica os marcos legais, através das Diretrizes Curriculares Nacionais para a Educação das Relações Étnico-Raciais e para o Ensino de História e Cultura Afrobrasileira e Africana (BRASIL, 2004), obrigando a inclusão no currículo escolar oficial dos estabelecimentos oficiais e particulares, em todo o Ensino Básico, o estudo da História da África, dos povos africanos e seus descendentes, da luta dos/as negros/as no Brasil, assim como o papel da cultura africana na

\footnotetext{
${ }^{3}$ É importante pontuar que em 2008 a Lei 10.639/2003 foi alterada pela Lei 11.645 que estabelece a obrigatoriedade do ensino de "História e Cultura Afro-Brasileira e Indígena". Entretanto, no presente artigo trabalharemos apenas a Lei 10.639 / 2003.
} 
formação da nossa sociedade. Exige, ainda, o estudo das brasilidades africanas, das africanidades brasileiras e da afrodiáspora nas Américas.

Tal lei caracteriza-se fundamentalmente por uma implicação com a promoção de uma educação comprometida com a diversidade cultural que constitui nossa sociedade, especialmente com a percepção de mundo africana, em virtude da sua preponderância em nossa construção social, cultural, política e econômica, e pelas muitas décadas de sua negação. Compreendemos que a valorização e o reconhecimento da diversidade cultural permeada de valores éticos e estéticos oriundos de encontros entre culturas indígenas, africanas e europeias que perpassam toda a constituição sociocultural do nosso país é basilar para a construção de uma sociedade igualitária, menos racista e mais inclusiva. Ronilda Ribeiro (1998, p. 62) nos chama a atenção para a proporção demográfica majoritária da população negra 4 após a brutal colonização das terras indígenas e a escravização dos africanos desterrados para o Brasil:

no período da escravidão, o número de indígenas era estimado em torno de um milhão e meio e o de africanos, três milhões e meio. Durante longos períodos da história do Brasil, o número de africanos e afro-descendentes foi bem superior ao de indígenas e brancos, fato que por si só explica a enorme influência e o papel decisivo da participação cultural africana no grupo social brasileiro.

Assim, ao buscar mudança nas diretrizes da política de educação, do currículo e das próprias ações do cotidiano, busca-se a práxis de uma política da africanidade que visa exercer "o poder para a promoção de um sistema de comunhão econômica e inclusão social, baseado na lógica própria de cada cultura [...]. A realização do bem viver de todos e de cada um" (OLIVEIRA, 2006, p. 130) e cada uma. Onde a cultura é constituída como - tecido que reveste nossa pele, lente pela qual percebemos os acontecimentos, pela qual conhecemos, além de ser meio de comunicação, de construção de identidades, de transformação, ressignificação, etc.

\footnotetext{
${ }^{4}$ Atualmente, segundo o IBGE, somos $55,4 \%$ da população brasileira, somando pretos e pardos
}

Revista Exitus, Santarém/PA, Vol. 10, p. 01-31, e020079, 2020. 
Há dezenas de anos que se tornaram constantes as reivindicações dos movimentos negros e intelectuais envolvidos/as nessa luta, além das denúncias de muitas escolas e universidades como espaços que perpetuam a exclusão da história e da cultura africana e afro-brasileira, transmitindo ainda em 2019 uma ideologia racista de subvalorização da nossa cultura, e supervalorização da cultura daqueles que nos colonizaram. Nesse sentido, o Parecer 03, das Diretrizes Curriculares Nacionais para a Educação das Relações Etnicorraciais e para o Ensino de História e Cultura Afro-Brasileira e Africana, de 10 de Maio de 2004,

\begin{abstract}
procura oferecer uma resposta, entre outras, na área da educação, à demanda da população afrodescendente, no sentido de políticas de ações afirmativas, isto é, de políticas de reparações e de reconhecimento e valorização de sua história, cultura, identidade. Trata, ele, de política curricular, fundada em dimensões históricas, sociais, antropológicas oriundas da realidade brasileira, e busca combater $o$ racismo $e$ as discriminações que atingem particularmente os negros. Nesta perspectiva, propõe à divulgação e produção de conhecimentos, a formação de atitudes, posturas e valores que eduquem cidadãos orgulhosos de seu pertencimento etnicorracial - descendentes de africanos, povos indígenas, descendentes de europeus, de asiáticos - para interagirem na construção de uma nação democrática, em que todos, igualmente, tenham seus direitos garantidos e sua identidade valorizada (BRASIL, PARECER N.: : CNE/CP 003/2004, p. 10).
\end{abstract}

Percebemos, então, que não é apenas uma questão de conhecermos a história africana antes, durante e / ou depois da colonização, não se trata somente de entender o pensamento social brasileiro desde a população africana afrodescendente, vai além, é uma questão de sensibilidade, de respeito e reconhecimento desse Outro lo povo negro e suas epistemologias) que foi por tanto tempo negado, mais que isso, teve sua própria humanidade negada.

A implementação da Lei destina-se às pessoas comprometidas com outros modos de educar / ser, pois a importância dos estudos decorrentes da História e da Cultura Africana e Afro-brasileira não é restrita à população negra, afrodescendente. Diz respeito a toda população brasileira, que se caracteriza por ser multicultural, pluriétnica, diversa. Munir-se de informações e subsídios sobre o tema, ajuda a desconstruir a formulação de concepções 
e conceitos baseados em ações racistas e preconceituosas, bem como comportamentos que reproduzem a falácia da democracia racial e a ideologia da branquitude.

É importante perceber a política curricular embutida na Lei, apresentando-a como uma ação que se mostra transversal não apenas aos componentes curriculares que formam o currículo pedagógico, mas à vida cotidiana. São políticas de sentidos, afeto, cuidado, pois têm a formação como princípio ético, primordial, compreendendo que ela "se apresenta ao mesmo tempo como autoformação, heteroformação e transformação" (MACEDO, 2010, p. 100, grifo do autor), delineando sua "expressão autopoética e práxica" (Idem). Não há possibilidade de acontecerem processos formativos sem afeto, sem poesia, pois é esta que busca os acontecimentos cotidianos, fazendo com que a práxis se construa de modo alterativo, com-partilhado.

Desse modo, a Lei 10.639 caracteriza-se por ser um instrumento de luta contra o racismo e a criminalização que aflige a população negra. Compreendemos que uma formação para o re-conhecimento da nossa ancestralidade e de nossa origem proporciona uma consciência política, cultural, ética e estética que nos leva a lutar contra o racismo e as barbáries que o mesmo origina, potencializando nosso pertencimento. Concordamos com Ronilda Ribeiro (1998, p. 65) quando ela diz que:

\begin{abstract}
O contato com a Ética e a Estética africanas necessariamente induzem sentimentos de orgulho de pertença étnica e racial nos afrodescendentes e nos brasileiros em geral. Resgatar a importância da mão e da voz africanas na construção física e simbólica desta terra brasileira é tarefa inadiável, à qual somos chamados hoje, como nunca antes. Lembrando o que foi ensinado por nossos ancestrais africanos: na grande rede de participação que caracteriza o universo estamos todos indelevelmente ligados.
\end{abstract}

A implementação da Lei faz-se na ação cotidiana, por meio de atos de currículos que aparecem como o "lugar da construção das hegemonias e re-existências, por processos híbridos, por contextualizações, descontextualizações e recontextualizações" (MACEDO, 2012, p. 73), onde "conteúdo e forma, instituído e instituinte são concebidos, refletidos e vividos 
cotidianamente" (Idem). Os acontecimentos cotidianos, aliados a escuta são fundamentais para a mudança das estruturas vigentes, onde a educação escolar e acadêmica ultrapassam suas paredes. Os atos de currículo trazem o processo de alteração incessante da base pedagógica de conteúdos, implicando políticas de sentido, políticas de conhecimentos diversos, luta por significados, necessitando, por consequência, a compreensão da natureza das alterações produzidas nas experiências formativas. Atos de currículos são ações contínuas do encantamento para afrorreferenciar o currículo e fortalecer, empoderar nosso pertencimento.

É importante pontuar que além da Lei 10.639 / 2003 tivemos outras conquistas significantes, como as Políticas de Cotas / Lei de Cotas ( $n^{\circ}$ $12.711 / 2012$ ) permitindo o acesso à Universidade a muitos homens e mulheres negros/as e de baixa renda, dentre tantas outras políticas de inclusão. Conscientização política e fortalecimento das identidades africanas implicando em ações que visam o combate ao racismo, à exclusão, a discriminação, ao preconceito e à conquista de uma realidade social digna e includente.

Lutamos pela aprovação da Lei 10.639 e a luta continua para a sua concretização, sua implementação, pois verificamos que muitas escolas e universidades não a aplicam, além de "esquecer" que ela é transversal a todos os componentes curriculares, aos acontecimentos em todos os espaços, não estando atrelado a uma data, componentes curriculares ou situações específicas. Temos diversas experiências positivas da sua implementação, mas precisamos amplia-las, implementar efetivamente.

Precisamos sair da visão de uma "história única", como nos chama a atenção Chimamanda Adichie, em sua palestra intitulada "Perigo de uma história única5". Conhecer outras histórias, reconhecer a história daqueles que nos formaram, que marcaram tão fortemente nossa cultura, permite-nos sair dessa história que se deseja única, monocultural, que se põe como

\footnotetext{
${ }^{5}$ Podemos assistir a essa palestra no seguinte endereço: http://www.youtube.com/watch?v=EC-bhlYARsc
} 
superior, universal e única, construída apenas por homens brancos e europeus.

Desse modo, a Lei 10.639 / 2013 é aqui compreendida como um conhecimento formativo, não limitado a ela mesma, pois é lida continuamente como atos de currículos que se constroem no cotidiano, nas conversas de corredores, nas aulas, em cada canto dos lugares eleitos formativos, educativos, assim como nas conversas de botecos, em casa, na rua... Esses atos dão subsídios para se discutir, refletir sobre as relações etnicorraciais existentes na atualidade, tira-nos do "não-lugar" e coloca-nos no lugar de construtores/as, de atores e atrizes sociais que podem e modificam a realidade onde vivemos. Pois os

\begin{abstract}
atos de currículo fazem parte da práxis formativa, trazem o sentido de não encerrar a formação num fenômeno exterodeterminado pela mecânica curricular e suas palavras de ordem, por consequência, não vislumbram os formandos e outros atores/autores da formação como meros atendentes de demandas educacionais, tão pouco aplicadores de modelos e padrões pedagógicos. (MACEDO, 2012, p. 72, grifos do autor).
\end{abstract}

Talvez compreender o Ensino de História e Cultura Africana e Afrobrasileira como atos de currículos denote um caminho mais objetivo, sem perder a subjetividade, pois, é o acontecer no ser / fazer, é o movimento das comunidades africanas e afrodescendentes que compreendem 0 conhecimento implícito na própria existência, assim fortalecemos os propósitos da Lei e continuamos na luta pelo respeito à diversidade.

Criação em conjunto, onde se educa a medida que se aprende, escutam-se as vozes de todos/as envolvidos/as, saindo da tradição de falar pelo Outro, pois "conceber currículos para o outro é a tradição que constituímos por séculos, por meio de uma atitude de autoridade com consequências drásticas para os segmentos sociais" (MACEDO, 2013, p. 63, grifo do autor). A atitude agora é conceber com o Outro, autorizar-se a construir, mas edificar com, pois "agregamos aqui a preocupação freireana de que toda vez que nos aventuramos e falamos pelo outro corremos um grande risco de depor contra ele" (Ibid, p. 64).

Queremos provocar diálogos, trocas efetivas e afetivas, com mútuas 
aprendizagens, perpassados pelos valores filosóficos africanos e que valorizem e ensinem a história contada desde os sujeitos que a vivenciam, não uma história como em nosso caso, onde se fala da escravatura e suas mazelas, mas não do conhecimento vasto do povo negro, africano e afrodescendente, das suas singularidades e riquezas, e quando fala, folcloriza, diminui e "embranquece".

Pretendemos agenciar uma educação que pensa e promove as relações etnicorraciais, buscando uma comunidade / sociedade justa, que valorize e respeite as singularidades e diversidades culturais e as pessoas que constituem tal comunidade, sociedade.

\section{Um currículo afrorreferenciado: alguns pontos de partida}

Um currículo afrorreferenciado está marcado pelas cosmopercepções, ou seja, modos de perceber e sentir, pensar de corpo inteiro; em outras palavras: corpo e pensamento em ação. Desse modo, tal currículo é delineado por nossas percepções e vivências oriundas de nossa ancestralidade africana, de seus valores e encantos que perpassam nosso cotidiano. Vanda Machado (2017, p. 142) chama a atenção para a necessidade de garantir significância do currículo, buscando sua interligação com o contexto local.

O currículo em uma escola não é tudo, mas deve ter a ver com tudo e com todos. Como construir uma prática que desconhece o lugar de onde se fala? Que desconhece para quem se fala? O currículo deve considerar a história, a cultura, as possibilidades e itinerância do outro e a sua própria.

O currículo afrorreferenciado (MACHADO, 2018; PETIT, 2016) traz uma perspectiva epistemológica plural, diversa e que tem o diálogo entre os saberes como preponderante, concebendo os saberes como horizontais, ou seja, diferentes e não melhor ou pior, inferior ou superior, não! Experimentação contínua para conhecer e assim transformar, pois a transformação só é possível pelo conhecimento.

Currículo este que encontra na diversidade a unidade de uma 
educação que escuta outras vozes, construindo-se em um movimento onde um não exclui o Outro, além de ter no contexto seu referencial maior, espalhando sabedoria/conhecimento pelo mundo. Onde "as teias do de dentro desenham uma rede com os fios dos de fora" (OLIVEIRA, 2007, p. 312), respeitando a encruzilhada própria das existências. O intento é "pensar a educação através do repertório cultural de origem africano e não simplesmente pensar o negro na educação brasileira (...). Trata-se, efetivamente, de criar outros referenciais - dinâmicos, inclusivos e criativos" (Ibid, p. 271). Referenciais esses que possam trazer a tona nossa ancestralidade, tirar o/a negro/a da periferia, reconhecer e produzir desde seus valores, suas conquistas e epistemologias, educar desde outros repertórios culturais e não desde um repertório único, "aprendendo-com e ensinando-com, aprendendo-a-aprender-com, a desaprender-com e a reaprender-com" (MACEDO, 2013, p. 65). Pois, "não cabe à ciência reivindicar superioridade absoluta e um lugar fora do mundo-vida, prática tão cara ao intelectualismo e ao cientificismo messiânicos" (MACEDO, 2006, p. 12).

Desse modo, a educação trançada nos acontecimentos da vida, relacionada às singularidades dos diferentes mundos, implica em diversas formas e modelos, pois que "a aprendizagem se realiza na e pela cultura" (MACEDO, 2013, p. 98). O currículo negro quer, então, pautar uma educação que carrega em si o saber ancestral de cada um/uma, ou seja, o saber da comunidade onde vive, da família, busca uma construção afetiva e efetiva entre a escola, a família e a comunidade. É coletivo, circular, pautado na convivência, na solidariedade, no cuidado e no conhecimento de si. Formação subjetiva que se objetiva na busca do bem viverb.

\footnotetext{
${ }^{6}$ Bem-Viver é um conceito filosófico oriundo da Filosofia da Libertação da década de 90. Segundo Euclides Mance (2013 apud MACHADO, 2014) "quando se trata da libertação e não apenas da liberdade, afirma-se que é necessário assegurar a todas as pessoas as condições econômicas, ecológicas, politicas, educativas, informativas e éticas para realizar as suas liberdades, tanto publicas quanto privadas". Para o autor expandir as liberdades implica na realização do bem-viver de cada um/uma e de todos/as, é então, "uma categoria filosófica muito importante para criticar toda forma de dominação e toda forma de libertação" (Idem).
} 
O currículo negro implica-se na construção de uma identidade pautada na própria história, na história do nosso povo, na nossa ancestralidade. Compreende que cada um, cada uma deve encontrar seu caminho e isso só é possível no coletivo, aprendendo ensinando e ensinando aprendendo.

Pois, para nós a educação faz-se em comunidade, com diálogo, o conhecimento é construído por toda a comunidade, "a educação africana não tinha a sistemática do ensino europeu, sendo dispensada durante toda a vida. A própria vida era educação" (BÂ, 2010, p. 200). Ou seja, é uma proposta educativa que se sintoniza com a concepção de Paulo Freire (1987, p. 62), pois:

\footnotetext{
a educação se faz uma tarefa altamente importante, uma vez que deve ajudar o homem a ajudar-se, colocando-o numa postura conscientemente crítica diante de seus problemas. Para tanto, é absolutamente indispensável à humanização do homem [...] não poderia ser feito nem pelo engodo, nem pelo medo, nem pela força. Mas, por uma educação que, por ser educação, haveria de ser corajosa, propondo ao povo a reflexão sobre si mesmo, sobre seu tempo, sobre suas responsabilidades, sobre seu papel no novo clima cultural da época de transição. Uma educação que the propiciasse a reflexão sobre seu próprio poder de refletir e que tivesse sua instrumentalidade, por isso mesmo, no desenvolvimento desse poder, na explicitação de suas potencialidades, de que decorreria sua capacidade de opção.
}

Educação compartilhada, que acontece no movimento do cotidiano. Onde todos têm o que ensinar e aprender, onde a escuta e a observação fazem-se preponderantes nessa caminhada. A educação na cultura africana tem como cenário o cotidiano, que é revestido do natural e do sagrado e a vivência é o modo principal de interação com essas duas dimensões. Daí que a ancestralidade se apresenta como esse espírito de intimidade com a natureza. A relação com a natureza supõe também um espaço comunitário. O ancestral é a natureza divinizada, é a referência cultural maior, é quem apreende a memória da comunidade, é o principal arquiteto na construção de uma vida comunitária saudável. Por isso, a natureza e os ancestrais são guias, sabedoria e diretrizes na(s) filosofia(s) africana(s) tradicionais. Inspirada nas cosmopercepções africanas surge, no 
panorama das pedagogias afrorreferenciadas, a Pretagogia, gestada na serra dos Inhamuns cearenses, entre os quilombos de Minador e Bom Sucesso que receberam o primeiro Curso de Especialização de Formação em História e Cultura Africana e Afro-brasileira, ocorrido inteiramente no espaço quilombola. Mas, antes de descrevê-la, entendamos o que motivou a sua criação.

\section{Desmontando o intento de desumanização pela força ancestral: aspectos político simbólicos do surgimento da Pretagogia}

Após essas considerações gerais importantes cabe pensar nas possibilidades concretas de instrumentalização de um currículo afrorreferenciado. Para tanto, construímos um referencial teórico metodológico que, partindo de uma trajetória de quase vinte anos, nos levou a sintetizar em alguns princípios o que passamos a denominar de Pretagogia, isto é, uma pedagogia empretecida que bebe essencialmente nas fontes das africanidades para a constituição do seu corpo teórico prático.

A Pretagogia tem vários motivos de surgimento. Um dos principais é de diminuir a imensa lacuna de conhecimento dos referenciais afro que perpassam nossa condição afrodiaspórica. O Brasil tem tido uma prática secular de apagamento das contribuições filosóficas, tecnológicas, econômicas, ético-estéticas e históricas, tanto dos povos originários indígenas como da população descendente de povos africanos, foco desse artigo. No que diz respeito particularmente a negras e negros que aportaram aqui à força, submetidos à condição de escravizadas/os, foi de perversidade extrema a obrigação coercitiva de anulamento de suas memórias, pertencimentos étnicos, referenciais ético-religiosos, laços de parentesco, maternidade, paternidade, a exigência de abandono de suas práticas culturais, sob pena de torturas com requintes de crueldade e/ou morte expeditiva. Sobreviver por mais um dia significava em grande parte aparentar desconsiderar a própria condição de ser pensante, atuante com história e vontade própria. 
É conhecida a famosa descrição do "iluminista" francês Voltaire, segundo o qual o espécime negro era definido como

\begin{abstract}
Um animal preto, que possui lã sobre a cabeça, caminha sobre duas patas, é quase tão destro como um símio, é menos forte do que outros animais de seu tamanho, provido de um pouco mais de idéias do que eles e dotado de maior facilidade de expressão. Ademais, está submetido igualmente às mesmas necessidades que os outros, vivendo e morrendo exatamente como eles. (VOLTAIRE, 1978b, p.62 apud SANTOS, 2002, p.27).
\end{abstract}

A partir do pressuposto do caráter animal de negras e negros, era justificada a suposta diminuta inteligência, a incapacidade sentimental e a ausência de espiritualidade da pessoa negra, lembrando diariamente da sua não humanidade. Agregava-se ao pressuposto de animalidade, o de objeto mercantil, mas com apreço inferior a sacos de arroz, feijão, ou farinha. Era preponderante fortalecer essa mercantilização atribuindo valores monetários às pessoas negras escravizadas, segundo suas supostas capacidades de rendimento laboral.

A título de compreensão mínima do grau de perversidade vivenciada pelos nossos ancestrais escravizados, desprezados e odiados para além do imaginável, basta uma visita ao Museu da deportação na llha de Gorée na Costa de Senegal, denominado Casa dos Escravos, com sua Porta de Não Retorno. A oportunidade de conhecer esse Memorial, apresentou-se em 2010, por ocasião do Festival Internacional de Artes Negras organizado por Senegal. No entreposto que servia de guarda aos mantimentos que seriam vendidos e transportados nos navios tumbeiros ultra mar, o andar de cima, organizado, limpo e arejado era o local de conservação de produtos como feijão, arroz, e farinha. Já no andar inferior, as "peças de mercadoria" negras eram simplesmente jogadas em buracos de pedra fria, sem luz e praticamente sem ar, divididas respectivamente entre homens, mulheres, "desválidos" (pessoas com deficiência, "peças" mais baratas e ainda mais descartáveis) e crianças (também mais "baratas" e descartáveis). Acorrentados no buraco cela, quase sem espaço, agachados e sem espaço para defecar, com péssima e escassa alimentação, os capturados eram permitidos apenas duas breves saídas diárias, sempre acorrentados, quando 
Ihes era jogada água. Era corriqueiro que se perdesse até metade da "carga" humana durante os longos dias ou semanas em que permaneciam nesse entreposto. Por fim, na hora do embarque, os sobreviventes desse primeiro martírio não tinham a chance de ver nada mais a não ser a estreita porta de não retorno que os levava do buraco até o navio. A intenção era que deixassem para trás de modo definitivo sua identidade, história, cultura, religiosidade, parentescos e pertencimentos. Sabe-se que era comum que chegasse em número inferior à metade a proporção de negros e negras levadas no tumbeiro ao "Novo" Continente Americano, para serem vendidos em solo brasileiro ou alhures, num mercado ao ar livre no porto de chegada. Já a mercadoria de alimentos e mantimentos não era estragada nem desperdiçada, o que nos diz muito sobre o grau de desprezo às pessoas negras, onde nem sequer a consideração mercantil de preservação da "carga" humana prevalecia sobre os requintes de crueldades.

Apesar da incrivel resiliência e resistência negra, que superou seu aniquilamento ao ponto de marcar profundamente a brasilidade, o país ainda vive uma forte herança do imaginário escravocrata, no que tange às mentalidades forjadas pelos intentos históricos de desumanização da pessoa negra e que atinge fortemente também as etnias indígenas. Todo esse imaginário de desumanização do não branco construído em mais de 500 anos, é algo que continua exigindo um largo esforço de catarse espiritual, não somente das pessoas negras vitimadas, mas também dos descendentes dos colonizadores europeus que nesse processo também se desumanizaram.

O processo de catarse e contraposição nunca deixou de acontecer, através das experiências comunitárias, solidárias, quilombolas, rebeldias/insurreições e Irmandades, das práticas e manifestações culturais, incluindo as religiosidades, e tantas outras formas de existência humana. A influência exercida por mais da metade da população $(55,4 \%$ de pretos e pardos, segundo O IBGE, 2017), sobre a idiossincrasia brasileira e todas as formas de filosofias (das oralidades às escrituras), tornam a implementação da lei 10639/03 um instrumento não apenas de política curricular, mas de reconhecimento do rico legado africano em todas as áreas de 
conhecimento e de produção de filosofia, num sentido ampliado do conceito europeu forjado do termo.

Entende-se assim o apagamento ou a invisibilização das contribuições das etnias negras para o processo civilizatório no Brasil, último país das Américas a abolir a escravidão, como parte de um sistema de inferiorização e aniquilamento brutal de sua humanidade, ideologia essa que se torna sustentáculo da perpetuação de sua subalternidade. O racismo à brasileira só sobrevive e justifica todas as mazelas que acometem a população negra, pelo processo de permanente estigmatização e desqualificação da porção africana da brasilidade e pela produção contínua de desconhecimento acerca das africanidades e suas valorações engrandecedoras. A continuidade da ignorância acerca das origens e contribuições africanas na constituição da brasilidade gera dois tipos complementares de alienação, por um lado o de brancos que vivem 0 mundo irreal dos privilégios imputados à cor branca - no sentido não somente diacrítico, mas também simbólico, sem dar-se conta da falácia da democracia racial, reproduzindo os preconceitos de modo naturalizado, ou pior, que se assumem declaradamente superiores, adotando deliberadamente a ideologia supremacista. Por outro lado, temos negros e negras com máscaras simbolicamente brancas que reproduzem o próprio preconceito anti negro (FANON, 2008), o típico caso do oprimido hospedando o opressor, como dizia Freire na Pedagogia do Oprimido, alguns chegando ao ponto de realizarem a necropolítica.

Face à história do escravismo e suas consequências atuais, temos uma larga trajetória repleta de resistências em todas as dimensões epistemológicas e da vida desde os movimentos de quilombagem, passando por diversas Revoltas como a dos Alfaiates, Balaiada, Revolta dos Malés, Revolta da Chibata, Irmandades do Rosário, Capoeiragem, Caldeirão, Guerra de Canudos, até movimentos culturais e religiosos, como candomblé e umbanda, samba, fundação do carnaval, blocos afros, movimentos negros como Frente Negra, MNU, UNEGRO, GRUCON, dentre muitos outros, lembrados em grandes marcos como a Marcha Zumbi dos 
Palmares em 1995 e a Marcha das Mulheres Negras em 2015 (Geledés, 2014 e Ribeiro, 2014).

Ciente da grandeza do povo negro brasileiro com sua história milenar africana muito anterior ao desterro forçado, a Pretagogia escolhe ressaltar as dimensões de produção de conhecimento, a criatividade e a ciência, fortalecendo a afirmação da ancestralidade, das existências e resistências, e sobretudo o encantamento gerado pelo que tem de mais precioso a brindar: sua força espiritual (Somé, 2003).

\section{Uma abordagem afrorreferenciada na busca da realização de um currículo negro: da experiência no quilombo até as formaçōes pretagógicas}

Em sala de aula na Universidade há mais de vinte anos Sandra Petit deparava-se com indícios dos resquícios da desvalorização do negro e da negra e de suas contribuições (Alves e Petit, 2015, p. 126):

Como quando, na sala de aula da Professora Sandra Petit, no Curso de Pedagogia, um dos estudantes associou a desigualdade socioeconômica no Nordeste e seu índice desfavorável de desenvolvimento à decorrência do menor percentual de imigração europeia nessa região, como se negros e indígenas não tivessem dado uma contribuição significativa à construção societária brasileira/nordestina. Triste foi perceber como boa parte dos estudantes concordava com essa afirmação, assumindo com naturalidade que a menor participação demográfica dos brancos fadava os nordestinos ao atraso socioeconômico.

Essas atitudes recorrentes levaram a uma aproximação com o Professor Henrique Cunha Jr e a criarmos anos depois, O NACE - Núcleo das Africanidades Cearenses, vinculado a FACED-UFC e no qual desenvolvemos pesquisas, formações e atividades de extensão. Em 2010 tivemos a oportunidade de realizar, junto com o Professor Cunha Jr. e a então doutoranda Geranilde Costa e Silva (hoje professora da UNILAB), um curso de especialização em História e Cultura africana e afro-brasileira para formação de professores de quilombo. Um grande diferencial desse curso foi o fato de acontecer integralmente no quilombo, no caso em duas comunidades do município de Novo Oriente, no Ceará. 
O curso teve 18 módulos contemplando, a nosso ver, as necessidades de um currículo negro, com especificidade quilombola: Conceito de Comunidade Quilombola, Conceito de Remanescentes de quilombo, Arquitetura nos Quilombos, Festas e Tradições Afrocearenses, Civilizações Africanas e História dos Afrodescendentes, Festas e tradições africanas, Consciência Corporal e Ancestralidade Africana, Filosofia da Ancestralidade Africana, Movimentos Sociais Negros, Métodos de Pesquisa e Ensino Afro, Prática de Intervenção Interdisciplinar Saúde Física e Espiritual no Quilombo, Religiões de Matriz Africana, Patrimônio Histórico Cultural, Projeto PolíticoPedagógico no Quilombo, Educação Infantil Afrodescendente e Ludicidade, Novas Tecnologias no Quilombo, Etnomatemática.

Outra marca importante do curso foi o enfatizar a "Cosmovisão Africana, tendo assim o corpo como fonte de conhecimento, daí a valorização da oralidade, da corporeidade e da arte, como, por exemplo, a dança e as marcas da cultura de raiz africana, ao lado da escrita e da leitura" (Fonte: Projeto do Curso).

Todos os conteúdos foram integrados de modo transversal dentro de uma concepção afrorreferenciada com o corpo como produtor de conhecimento. Durante essa experiência forte e intensa que durou aproximadamente dois anos, notamos como conseguimos reverter tendências negadoras da negritude entre os cursistas em atitudes de autoafirmação negra no final da formação. Isso só foi possível pela ênfase na atitude desde dentro. Pois percebemos que:

há mais do que dificuldade de enxergar o negro, há sobretudo uma dificuldade de tomar isso para si, de apropriar-se da negritude com naturalidade, como resultado tanto de linhagem e história e memória, como de vivência, território e referência cultural. Para reverter essas tendências negadoras, precisamos suscitar nas pessoas um sentimento de pertencimento à ancestralidade africana (...), esse sentimento é transmitido principalmente por nosso corpo, pois ele é guardião da nossa memória ancestral (PETIT, 2015, p.148).

E assim foi realizar não apenas um currículo instrutivo, repleto de informações e conhecimentos de grande relevância heurística, mas também de relevância político existencial tocando o íntimo das pessoas, provocando 
- que Sobonfu Somé (2003) chama de senso de propósito, senso de pertencimento e senso de comunidade, fortes heranças africanas. Essas três dimensões do currículo nos parecem tão importantes quanto os conteúdos propriamente instrutivos e têm guiado nosso trabalho desde então.

Eis alguns dos dispositivos que nos permitem trabalhar essas três dimensões da força ancestral negra geradora de autoafirmação e orgulho das africanidades, independentemente do fenótipo das pessoas engajadas nessa formação:

- O levantamento dos marcadores das africanidades na vida das pessoas, negras e não negras, desde a tenra idade até a idade atual. Chamamos de marcadores das africanidades aquilo que identificamos como formas de ser, pensar, agir, e produzir conhecimento. Petronilha Beatriz da Silva considera o conjunto de raízes da cultura brasileira que originaram na África que está presente nas práticas cotidianas de negros e não-negros (SILVA, 2005). Já Kabengele Munanga (2007) trata do rosto comum que se depreende da enorme diversidade cultural africana. São traços, artefatos, processos identificadores das nossas cosmopercepções africanas. A título de instrumentalização levantamos trinta marcadores, que não pretendem ser exaustivos, mas que nos ajudam a identificar nossos pertencimentos, pela tabela a seguir.

Tabela 1: Marcadores das Africanidades

\begin{tabular}{|l|l|}
\hline 1 - História do meu nome & 16 - Danças afro \\
\hline $\begin{array}{l}2 \text { - Histórias da minha linhagem, inclusive } \\
\text { agregados }\end{array}$ & $\begin{array}{l}17 \text { - Cabelo afro } \\
\text { (encaracolado/cacheado/crespo) - } \\
\text { práticas corporais de afirmação e negação } \\
\text { dos traços negros diacríticos }\end{array}$ \\
\hline $\begin{array}{l}3 \text { - Mitos/lendas/o ato de contar/valorização } \\
\text { da contação }\end{array}$ & $\begin{array}{l}18 \text { - Representações da África/relações } \\
\text { com a África }\end{array}$ \\
\hline $\begin{array}{l}4-\text { Histórias do meu lugar de } \\
\text { pertencimento/comunidade/Territorialidades } \\
\text { e desterritorialidades negras (movimentos de } \\
\text { deslocamentos, geográficos, corporais e } \\
\text { simbólicos) }\end{array}$ & \\
\hline $\begin{array}{l}5-\text { Sabores da minha infância - pratos, } \\
\text { modos de comer e o valor da comida }\end{array}$ & 20 - Artesanatos \\
\hline $\begin{array}{l}6-\text { Pessoas negras referência da minha } \\
\text { família e da minha comunidade e pessoas } \\
\text { negras referência do mundo, significativas } \\
\text { para mim }\end{array}$ & 21 - Outras tecnologias \\
\hline
\end{tabular}




\begin{tabular}{|c|c|}
\hline $\begin{array}{l}7 \text { - Simbologias da Circularidades: tempos } \\
\text { cíclicos e da natureza }\end{array}$ & 22 - Valores de família/filosofias \\
\hline $\begin{array}{l}8 \text { - Práticas e valores de Iniciação/Ritos de } \\
\text { transmissão e ensino }\end{array}$ & 23 - Racismos (perpetrados e sofridos) \\
\hline $\begin{array}{l}9 \text { - Mestras e Mestres negras/negros (da } \\
\text { cultura negra) }\end{array}$ & $\begin{array}{l}24 \text { - Formas de conviver/laços de } \\
\text { solidariedade/relações de comunidade }\end{array}$ \\
\hline 10 - Escrituras Negras & 25 - Relação com a natureza \\
\hline 11 - Curas/Práticas de saúde & 26 - Religiosidades Pretas \\
\hline 12 - Cheiros "negros" significativos & $\begin{array}{l}27 \text { - Relação com as mais velhas e os mais } \\
\text { velhos }\end{array}$ \\
\hline $\begin{array}{l}13 \text { - Festas afro da minha infância e festas } \\
\text { de hoje }\end{array}$ & 28 - Vocabulário/formas de falar \\
\hline $\begin{array}{l}14-\quad \text { Lugares míticos e territórios } \\
\text { afromarcados (investidos pela negritude) }\end{array}$ & $\begin{array}{l}29 \text { - Relação com o chão (vivências e } \\
\text { simbologias) }\end{array}$ \\
\hline $\begin{array}{l}15-\text { Músicas/cantos/toques/Ritmos/estilos } \\
\text { afro }\end{array}$ & $\begin{array}{l}30 \text { - Outras Práticas corporais (brincadeiras } \\
\text { tradicionais/jogos e outros) }\end{array}$ \\
\hline
\end{tabular}

Fonte: Alves e Petit, 2015.

- Diversos exercícios de simbolização dos nossos pertencimentos: recorrendo a imagem da árvore, preferencialmente do baobá, enquanto representante máximo de longevidade (pode viver até 6000 anos), senhoridade (respeito aos mais velhos), de raízes profundas e tronco largo, agregador de grandes rodas em seu entorno, galhos em forma de braços alçados ao céu em eterna reverência e interpelação divina; pedimos para compor a árvore, além de frases de narrativas, desenhos, fotos ou cópias de fotos, objetos ou fotos de objetos, artes em massinha. Em outras ocasiões deixamos produzirem a árvore que sai da imaginação e conversamos sobre as diversas metáforas que decorrem do desenho/cores/detalhes. Havendo mais tempo de elaboração, sugerimos a realização de uma árvore individual de seus afrossaberes e história de negritude, em seguida propomos que sejam percorridos no Museu floresta dos afrossaberes criado pelos educandos e educandas, onde podemos ler a diversidade de conceitos e trajetórias de vida. A árvore tem sido também trabalhada de forma temática, trazendo os valores e práticas comunitários da sábia Sobonfu Somé (2003; PETIT, 2018), e do griot Sotigui Kouyaté (BERNAT, 2013), onde, a partir de frases extraídas de livros pedimos para relacionarem com as práticas comunitárias de seus contextos de vida, formando uma árvore literalmente de palavras, com sentido comunitário e complementando com desenhos. 
- A musicalidade como fala forte, veículo de busca da afetividade, empatia e significância das africanidades nas nossas vidas, tanto no sentido pessoal como coletivo, como fazemos no dispositivo Minha música, Meu pertencimento: através da escolha de uma música afro predileta, cada um/a se apresenta, explicitando o porquê da opção por essa música, o contexto pessoal e/ou social que a torna significativa, o que nela afeta, produz sentido e memória. Incentiva-se a buscar aprofundamentos sobre compositor/a, intérprete da música, contexto de surgimento da mesma, os sentidos coletivos, culturais ou micropolíticos que encerra. Podem surgir verdadeiras aulas de história a partir de uma música escolhida, mas também afetos poderosos, afirmações, momentos de saída do armário (desde questões de identidade de gênero até marcadores fortes como descoberta de sua negritude reprimida, escondida ou negada, cabelos em processo de libertação, reflexão sobre seu lugar na estrutura familiar, e tantos outros elementos que levam a choros, risos, explosões de sentimentos e consciências a flor da pele).

- No item escrituras negras, incentivamos o uso de ideogramas perpassados de significados ético-filosóficos como os adinkras ganenses das etnias akan, refletindo valores africanistas a partir desses desenhos também entendidos como escrituras, marcas das ancestralidades e da oralidade como fontes de conhecimento profundo; chegamos inclusive à produção de parangadinkras, ou seja, um misto do Parangolé de Hélio Oiticica com os adinkras akan, com o qual se pode (re)vestir o conhecimento ancestral a partir de uma mensagem ético-filosófica, desenvolvendo seus significados ou inventando novos adinkras portadores de filosofias afroancestrais atualizadas hoje. Fora o uso de adinkras, incentivamos Parangolés formados por outras narrativas pictóreas como no Parangolé Afroquilombola (SILVA, 2015) que conta a história, usos e costumes de uma comunidade quilombola, produzida de forma intergeracional pelos membros da localidade e gerando exposições em Museu e, aqui de novo, a contação ambulante de sua história ao vestir a indumentária realizada em coautoria. 
- A produção de narrativas, sobre a história familiar clânica, envolvendo adotados e agregados, e refletindo sobre as ausências negras ou estigmas associados a determinados escamoteamentos, ou sumiços da memória "oficial" da árvore genealógica, o sumiço de pessoas negras das fotos de família ou simples inexistência simbólica, mas também o contrário, a grandiosidade de pessoas negras referências, a irmandade, a força de resiliência lá encontrada; tais narrativas exigem investigações autobiográficas que não iniciam na minha pessoa, e sim, a exemplo de Hampâté Bâ, no livro O Menino Fula (2003), na conexão com os ancestrais, próximos ou longínquos, incluindo sempre, agregadas e agregados;

- Tardes na Tabanka7 (ou Manhãs/Noites) realização de contações das mais diversas, desde as míticas, as africanas, até lendas e histórias afro-brasileiras, antigas ou contemporâneas, trazendo a linguagem da gestualidade, eventualmente com musicalidade (canto e/ou toque), mas sempre com profundidade de ensinamento. Contações estas que precisam nos reportar ao conhecimento milenar que herdamos sobre nossa espécie humana e suas problemáticas na busca de nos entendermos como seres éticos, construtores de um senso de comunidade e de bem viver. É o momento de compreender o sentido educativo profundo, de contadoras e contadores enquanto aconselhadores/as e guias espirituais que nos mantêm em conexão comunitária, em torno de um ato iniciático;

- A ritualização em rodas de dança coletiva (Roda Dança Afroancestral) onde cada dança realizada coletivamente, envolvendo os mais diversos ritmos afros (reggae, rap, axé, chorinho, samba, salsa, reggaeton, música haitiana, merengue dominicano, Pata Pata sul-africano, dancehall, tambor de crioula, cumbia, ijexá, maracatu, trova e seresta cubana, jazz, etc), a vontade, conforme suas preferências, é pretexto para aulas de contextualização do ambiente e motivação da dança, das letras das

7 A palavra Tabanka em crioulo significa "aldeia", remete às aldeias do interior. Mas, também é, em Cabo Verde, uma manifestação cultural de resistência, uma espécie de irmandade que surgiu em resistência à colonização. É uma forma de canto e uma festa que acontece na llha de Santiago. Além disso, tabanka, na Guiné-Bissau também é usada em um sentido mais amplo de tudo o que é relacionado às tradições, a forma de viver comunitariamente em sintonia com essas tradições. 
músicas e sobretudo dos significados embutidos na linguagem corporal e movimentação realizada. Momento de júbilo e de reconhecimento da dança como fundamento da espiritualidade africana, do corpo em eterna gratidão pelo dom da vida, e da força de realização (também chamada de axé); Sandra Petit tem usado esse procedimento para apresentar-se a alunas e alunos que participam do componente curricular Cosmovisão Africana e cultura dos afrodescendentes no Brasil. Em sendo cubana, tem trazido referências de músicas cubanas como Caridad8 de John Santos y el Coro Folclórico Kindembo, um grupo cubano que toca música que mistura santeria (candomblé cubano) com ritmos "profanos", que trata da relação entre Oxum e sua versão sincretizada Virgen de la Caridad, trazendo de modo poético vários marcadores das africanidades ioruba. Outro exemplo dessa playlist, é a música Negrito Bembón` (Nego Beiçudo, gíria pejorativa) que denuncia a virulência do racismo nas Américas, ao narrar de forma aparentemente cómica, o assassinato de um negro pelo simples motivo de ter lábios grossos, insistindo "mas isso não é motivo", letra do cantor portoriquenho Ismael Rivera baseado num fato real ocorrido em Porto Rico e cantado nesse CD pela voz incrível da diva cubana Celia Cruz.

Desses exemplos, dos numerosos dispositivos implementados como ponto de partida para o restante das temáticas trabalhadas nas nossas formações de professores e nas intervenções com escolares e quilombolas, como capoeira, literatura oral, literatura negra, pretuguês (nosso português africanizado), história dos afrodescendentes, filosofias africana, vestuário afro, cabelo, etnomatemática (ou afromatemática), práticas de cura/medicina ancestral, religiosidades pretas, dentre outras, o que entendemos ao longo de mais de quinze anos, é que não podemos prescindir no currículo afro ou negro de quem somos, o que queremos ser e o que nos legaram os ancestrais.

Isso significa dizer que, seja qual forem as temáticas subsequentes, o currículo negro é aquele que traz além dos fatos e elementos instrutivos de

8 Do cd "Hacia el Amor" (1996). Vide a música no final do texto.

9 Vide a música no final do texto. 
todo o conhecimento, uma forma diferenciada de ensino aprendizagem que inevitavelmente se inspira nas nossas cosmopercepções. Mas, antes de mais nada, potencializam os pertencimentos afro abafados, reprimidos pela política secular de apagamento, ou como dizia Lélia Gonzalez, de denegação.

Assim, antes de conhecer, procuremos nos pertencer, pois o conhecimento que não mexe no senso de pertencimento afro corre o risco de se transformar em mera abstração ou atalho para obtenção de certificado, mantendo o elo de colonialidade de relegação do corpo e da oralidade ao seu nicho de folclore inferiorizado. Não somente os conteúdos, mas também a forma de transmissão precisam andar juntos, não mais de forma hierarquizada e bancária, mas preferencialmente iniciática, no seu sentido amplo.

Finalizando, queremos mostrar quais conceitos operatórios temos identificado na produção de um currículo negro, ainda não aplicado de forma integrada à escola e a universidade, por falta de oportunidade, mas que já experimentamos ao longo dos anos de docência, formação, extensão e em múltiplas intervenções pedagógicas realizadas por nós, e também por todo um grupo de pretagogas e pretagogos, e estudiosos e estudiosas de abordagens das Filosofias da Ancestralidade e do Encantamento, desde a Filosofia Africana.

\section{Dos princípios da Pretagogia e alguns dos seus conceitos operatórios}

De todos esses percursos podemos realizar uma síntese dos principais conceitos operatórios que consideramos necessários a serem levados em consideração, alguns dos quais nos permitimos criar para darmos conta da sistematização teórica dessa experiência. Para tanto partimos dos princípios da Pretagogia:

como já foi citado, é um referencial teórico-metodológico que vem sendo construído há alguns anos e que toma os valores e saberes afrorreferenciados como elementos aglutinadores e condutores das experiências de ensino-aprendizagem. Por compreender que as trajetórias dos afrodescendentes têm especificidades históricas e 
sociais, a Pretagogia traz em seus referenciais uma diversidade de expressões afrodescendentes, tais como: 1) o autorreconhecimento afrodescendente; 2) a tradição oral: 3)a apropriação dos valores das culturas de matriz africana; 4) a circularidade; 5) a religiosidade de matriz africana entrelaçada nos saberes e conhecimentos; 6) o reconhecimento da sacralidade; 8) o corpo como produtor espiritual, produtor de saberes; 7) a noção de território como espaço-tempo socialmente construído; 8) o reconhecimento e entendimento do lugar social atribuído ao negro. (ALVES E PETIT, 2015, p. 126)

- Pertencimento Afro: mediante exercícios de Enraizamentos (memoriais) materializados em diversas linguagens (escritas, plásticas / gestuais / verbais e corporais) e mobilizados pelas categorias de Corpo memória e Corpo Chão inerentes ao Corpo-Dança Afroancestral, podemos realizar a conexão com a Ancestralidade Africana que intentaram aniquilar e/ou desqualificar. A descoberta da nossa grandeza como povos de histórias milenares cuja presença no planeta já foi cientificamente comprovada como primeira, deve nos imbuir de um senso de responsabilidade e afirmação do nosso propósito existencial. No currículo é necessário alimentar esse elemento que por motivos históricos gerou o conhecido complexo de vira lata brasileiro que termina nos atingindo a todos de forma por vezes muito nefasta, reduzindo nosso potencial de vida.

- Espiritualidade na perspectiva africana ou afrodiaspórica: tratamos aqui essa noção como conjunto de valores, atitudes e práticas que nos foi passada pela Ancestralidade e que nos guiam ou podem guiar até hoje pela sua força de ensinamento. Embora as sociedades estejam em constante mudança, há elementos do nosso senso de comunidade que pouco se transmutam por envolver a nossa humanidade no que tem de mais profundo. São fundamentalmente ensinamentos que ensejam contribuírem para o bem viver e o bem estar da comunidade, respeitando e promovendo conexão com os antepassados, mas ainda mais com o cosmos e todas as forças que movem o mundo a partir de uma energia primordial insondável e misteriosa que alguns intitulam Deus, Zambi, Olorum, ou tantas outras denominações existentes no mundo. Até para um ateu é possível fazer sentido por existir o reconhecimento aí da nossa impossibilidade de controlar e conhecer o todo. É a humildade da aceitação de algo insondável e que a 
mente humana não pode alcançar. E ainda que nós não somos o centro do universo, pois não existe centralidade do ser humano e sim interconexão com a natureza e todo o cosmos. O importante da Espiritualidade, não é o culto religioso em primeiro lugar, e nem as denominações que possam ser dadas, e sim uma atitude e postura a ser vivida, sentida e repassada. No currículo negro que queremos a espiritualidade se apresenta sob formas de empatia com o Outro e na forma de corpo coletivo, onde convivemos, pois como diz Sobonfu Somé, tolerar o outro é só evitar de matá-lo fisicamente. Por isso, a Espiritualidade é inseparável da Comunidade, do senso que formamos um corpo coletivo unidos nas suas diferenças e singularidades por essa compreensão.

- Ancestralidade: Vai para além do culto aos nossos antepassados, e a manutenção da história clânica e das nossas linhagens biológicas, envolvendo formas de cultivar também linhagens simbólicas que fortalecem nossos laços comunitários. Um exemplo é a capoeira, onde nos ligamos a mestres e mestras que transmitiram conhecimentos numa linhagem de família não sanguínea (como na expressão "meu avô de capoeira"). O senso de ancestralidade é fundamental na arkhé africana que só se sustenta através de práticas, rituais e vivências que atualizam constantemente nossos laços. No currículo negro essa dimensão é primordial para a compreensão de seu lugar na Existência.

- Afrotransversalidade: trabalhando o princípio que guia a oralidade como método e filosofia, o estudioso Hampâté Bá preconiza não segmentar o conhecimento em fatias, evitando a disciplinarização (BÂ, 2010; 2003). Assim, procuramos trazer de modo entrelaçado diversas ciências, tecnologias, junto com saberes de experiência, alguns milenares, sempre levando em consideração a Espiritualidade, levando-nos ao respeito do nosso Corpo Coletivo, mediante práticas de auto cuidado e cuidado do outro e do cosmos. Esse currículo negro tranversalizado encontra sua integração nos valores ancestrais e na percepção das relações de circularidade entre saberes e áreas de conhecimento. 


\section{Tessituras in-conclusivas: o que quer um currículo afrorreferenciado?}

O currículo negro que queremos é trabalhado numa perspectiva de um/a contador/a de histórias, de um griot ou griote que sai pelo mundo narrando histórias e adaptando-as aos lugares por onde passa, dedicandose a ensinar por meios dos conhecimentos das próprias comunidades, dos ancestrais, perpetuando movimentos éticos de inclusão e reconhecimento, tornando o aprender / educar um ato contínuo e prazeroso, trazendo os acontecimentos do cotidiano como primordial para o conhecer / aprender. Porquanto, assim como a história se faz na e pela sociedade, a produção científica não é excepcionalmente dos/as cientistas, mas de toda a comunidade. Desse modo, o intento é o de compartilhar conhecimento, qualquer que seja ele, pois só assim valoriza-se a diferença, a pluralidade e o múltiplo. Um currículo negro busca nas abordagens afrorreferenciadas o que a colonialidade Ihe rechaça, a partir do corpo coletivo.

Pensar / refletir / ter o conhecimento como afrorreferenciado é ter a tradição, a ancestralidade como guia, é reconhecimento e manutenção desse chão que reinventa incessantemente nosso existir em um mundo que continuamente nega nossa existência... conhecimento afrorreferenciado é respeito pela diversidade, integração, tradição, e ancestralidade, os princípios da filosofia africana (MACHADO, 2014). Princípios esses abertos a todas e todos, conforme a circularidade de suas práticas e valores, independentemente de fenótipo porque dialoga com todo seu entorno, sem hierarquizações e exclusões. Enfim antes de uma questão de cor, é uma atitude diante da vida, uma grande Roda Dança AfroAncestral convidativa, cheia de encantos. 


\section{El Negro Bembón Celia Cruz}

Mataron al negro bembón Mataron al negro bembón Hoy se llora noche y día

Porque al negrito bembón Todo el mundo lo quería Porque el negrito bembón Todo el mundo lo queria

Y llegó la policía

Y arrestaron al matón

Y uno de las policías

Que también era bembón

Le toco la mala suerte

De hacer la investigación

Le toco la mala suerte

De hacer la investigación

Y saben la pregunta Que le hizo al matón Por qué lo mató?

Diga usted la razón

Y saben la respuesta

Que le dio el matón:

Yolo maté

Por ser tan bembón

El guardia escondió

La bemba y le dijo:

Eso no es razón

\section{Caridad}

John Santos y el Coro Folclórico Kindembo

Beroni Abebe Osun

Beroni Abebe leda
Beroni Abebe Osun

Beroni Abebe leda

Iyá yumo, braka ia ieda

Beroni Abebe Osun

Que hermosa estás, Cari

Cuando sales a bailar

Tu naturaliza tan sútil

Como el vaivén del palmar.

$A$ veces me hace llorar

Lágrimas de Alegria

Tú que me has dado la vida Y también lo que es amar Ay, pero que bonita estás Cari. Hasta los movimentos Que evocan los sentimentos Profundos y espirituales

Eres la Caridad del Cobre,

Yeye karé omi yeye o,

Vienes de la África lejana

Alaberte es mi deseo;

Pero dicen que tú eres vana Mi Reina Morena

No saben que representras

La hermosura antillana

Que preciosa está

Mi morena Caridad.

lyá Modupé

Tu presencia es celestial

Tú eres la dama entre damas

De la tierra lyesá

De la majestade real

Del água pura y clara

Me remoza tu mirar

$Y$ me hace sonreir,

Es um milagro sentir

Tu presencia celestial. 


\section{Referências}

ALVES, Kellynia Farias; PETIT, Sandra Haydée. Pretagogia, pertencimento afro e os marcadores das africanidades: conexões entre corpos e árvores afroancestrais. In: ALVES, Kellynia Farias; MACHADO, Adilbênia Freire; PETIT, Sandra Haydée (Orgs). Memórias de Baobá II. Fortaleza: Imprece, 2015.

BÂ, Amadou Hampâté. A tradição viva. In: História Geral da África, I: Metodologia e pré-história da África / Editado por Joseph Ki-Zerbo. 2.ed.rev. - Brasília: UNESCO, 2010.

2003.

Amkoullel, o menino fula. São Paulo: Pallas Athenas: Casa das Áfricas,

BERNAT, Isaac. Encontros com o griot Sotigui Kouyaté. 1. Ed. Rio de Janeiro:

Pallas, 2013.

BRASIL. Ministério da Educação. Secretaria de Educação Continuada, Alfabetização e Diversidade. Parecer CNE/CP 003/2004. Diretrizes

Curriculares Nacionais para a Educação das Relações Étnico-Raciais. Brasília: MEC, 2004. Disponível em:

http://portal.mec.gov.br/cne/arquivos/pdf/003.pdf

FANON, Frantz. Pele negra, máscaras brancas. Salvador: EDUFBA, 2008.

FLOR DO NASCIMENTO, Wanderson. Outras vozes no ensino de filosofia: $O$ pensamento africano e afro-brasileiro. Revista Sul-Americana de Filosofia e Educação. Número 18: maio-out/2012, p. 74-89. Acesso em 01 de Junho de 2012.

FREIRE, Paulo. Pedagogia do Oprimido. 17ª. Ed. Rio de Janeiro: Paz e Terra, 1987.

MACHADO, Adilbênia Freire. Filosofia Africana tecendo saberes ancestrais e encantados: conhecimento afrorreferenciado. In: Lucas Súllivam Marques Leite... [et al.] (Orgs.). Ensino e Formação: novas perspectivas para o cotidiano. Mossoró - RN: EDUERN, 2018.

Ancestralidade e Encantamento: filosofia africana mediando a história e cultura africana e afro-brasileira. 2014. 240f. Dissertação (Mestrado em Educação) - Universidade Federal da Bahia. Salvador - BA, 2014. MACHADO, Vanda. Prosa de Nagô: educando pela cultura. 2a. ed. Salvador: EDUFBA, 2017.

MACEDO, Roberto Sidnei. Atos de Currículo e Autonomia Pedagógica: o socioconstrucionismo curricular em perspectiva. Petrópolis, RJ: Vozes, 2013. 
A etnopesquisa implicada: pertencimento, criação de saberes e afirmação. Prefácio de Nilda Alves. Brasília, Liber Livro, 2012.

. Compreender/mediar a formação: o fundante da educação. Prefácio de Marie-Christine Josso; apresentação de Jacqueline MonbaronHouriet. Brasília: Liber Livro Editora, 2010.

Editora, 2006.

Etnopesquisa crítica, etnopesquisa-formação. Brasília: Líber Livro

MUNANGA, Kabengele. O que é Africanidade? In: Revista Biblioteca

Entrelivros - Vozes da África. São Paulo, Duetto, edição especial, n. 6, p. 8-13, 2007.

OLIVEIRA, Eduardo David de. Filosofia da ancestralidade: corpo e mito na filosofia da educação brasileira. Curitiba: Editora Gráfica Popular, 2007.

Cosmovisão africana no Brasil: elementos para uma filosofia afrodescendente. Curitiba: Editora Gráfica Popular, 2006.

PETIT, Sandra Haydée. Na roda, ao convite do Espírito: Ancestralidade e Comunidade na Filosofia de Sobonfu Somé. In: SILVA, Joselina da (org). 0 pensamento de/por mulheres negras. Belo Horizonte: Nandyala, 2018.

Práticas Pedagógicas para a Lei N 10.639/2003: a criação de nova abordagem de formação na perspectiva das africanidades. In: Educ. Foco, Juiz de Fora, v.21, n.3, p. 657-684, set. / dez. 2016.

Pretagogia: Pertencimento, Corpo-Dança Afroancestral e Tradição Oral. Contribuições do Legado Africano para a Implementação da Lei $n^{\circ}$ 10.639/2003. Fortaleza: EdUECE, 2015.

RIBEIRO, Matilde. Políticas de promoção da igualdade racial no Brasil (1986 2010). 1. Ed. Rio de Janeiro: Garamond, 2014.

RIBEIRO, Ronilda lyakemi. De Boca Perfumada a Ouvidos Dóceis e Limpos: Ancestralidades Africanas, Tradição Oral e Cultura Brasileira. Itinerários, Araraquara, $\mathrm{N}^{\circ} 13,1998$.

SANTOS, Gislene Aparecida dos. A invenção do Ser Negro. São Paulo / Rio de Janeiro. Ed. Pallas, Fapesp, 2002.

SILVA, Cláudia de Oliveira da. Construindo o pertencimento afroquilombola através das contribuições da pretagogia no quilombo de Serra do Juá Caucaia - Ce. 2016. 111 f. Dissertação (Mestrado em Educação) Universidade Federal do Ceará. Fortaleza - CE, 2016. 
SILVA, Petronilha Beatriz Gonçalves e. Aprendizagem e Ensino das Africanidades Brasileiras. In: MUNANGA, Kabengele (Org.). Superando o

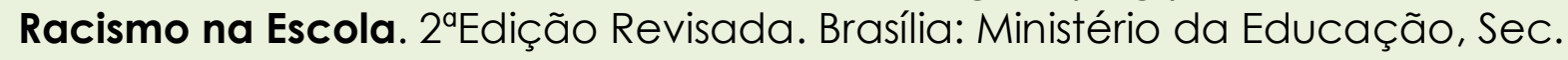
de Educação Continuada, Alfabetização e Diversidade, 2005.

SILVA, Tomaz Tadeu da. O currículo como fetiche - a poética e a política do texto curricular. 1. ed. 4.reimp. Belo Horizonte: Autêntica, 2010.

SOMÉ, Sobonfu. O Espírito da Intimidade: ensinamentos ancestrais africanos sobre relacionamentos. SP: Odysseus Editora, 2003.

Manifesto da Marcha das Mulheres Negras 2015 contra o Racismo e a Violência e pelo Bem Viver. Texto de 25 de julho de 2014. Acessado dia 27 de julho de 2014 In: https://www.geledes.org.br/manifesto-da-marcha-dasmulheres-negras-2015-contra-o-racismo-e-violencia-e-pelo-bem-viver/\#

Recebido em: 21 de fevereiro de 2020

Aprovado em: 20 de junho de 2020

Publicado em: 01 de setembro de 2020 